\title{
Contribution of thermal expansion and "diffusive" modes to isobaric thermal conductivity of rare gas solids
}

\author{
O.I.Pursky ${ }^{1}$, V.A.Konstantinov ${ }^{2}$ \\ 1 Taras Shevchenko National University of Kyiv, Faculty of Physics, 6 Glushkova Ave., Kyiv 03022, Ukraine \\ 2 Institute for Low Temperature Physics and Engineering of the National Academy of Science of Ukraine, \\ 47 Lenin Ave., Kharkov 61103, Ukraine
}

Received December 11, 2006

\begin{abstract}
A theoretical model is developed to describe the experimental results obtained for the isobaric thermal conductivity of rare gas solids (RGS). The isobaric thermal conductivity of RGS has been analysed within Debye approximation with regard to the effect of thermal expansion. The suggested model takes into consideration the fact that thermal conductivity is determined by U-processes while above the phonon mobility edge it is determined by "diffusive" modes migrating randomly from site to site. The mobility edge $\omega_{0}$ is determined from the condition that the phonon mean-free path restricted by the U-processes cannot be smaller than half of the phonon wavelength.
\end{abstract}

Key words: thermal conductivity, phonon interactions, "diffusive" modes

PACS: $66.70 .+f, 63.20 . L s$

\section{Introduction}

In the high temperature region, at Debye temperature $\left(\Theta_{\mathrm{D}}\right)$ and higher, the thermal conductivity of perfect crystals is determined mainly by phonon-phonon interactions. However, with the increased complication of crystalline structure, there appear new types of thermal motions, which are capable of affecting the thermal conductivity and thus complicate the analysis of its temperature dependence [1]. In this respect, the solidified inert gases are very convenient objects in order to compare the experimental results with the theory, since in this case, the lattice dynamics does not get complicated by the contribution of optical phonons, librons, and by the effects related to structural disorder. It is generally known that according to the theoretical predictions [2], the lattice thermal conductivity should be inversely proportional to temperature $\Lambda \propto 1 / T$ at $T \geqslant \Theta_{\mathrm{D}}$. However, as early as in the first experimental studies the results have been obtained, which cannot be described within the framework of existent theoretical models of heat transfer $[2,3]$. Both isobaric and isochoric thermal conductivities of RGS possess the temperature dependence that considerably differs from the $1 / T$ one [3]. At isochoric conditions, the thermal conductivity depends on temperature much slower than $1 / T$ [4]. This is connected with the fact that the mean free path of phonons in these substances becomes of the order of interatomic distance at premelting temperatures [4]. The analysis of experimental data $[1,5-7]$ for isobaric thermal conductivity points to some typical tendencies in the behavior of its temperature dependences. In the given temperature range, the experiments at constant pressure showed that the thermal conductivity varied more rapidly than $1 / T$.

In the present paper, we concentrate on the quantitative analysis of high temperature isobaric thermal conductivity in solid Ar, Kr, and Xe. Simulation was carried out within the framework of Debye approximation by using the concept of the lower limit of thermal conductivity and taking into account the effect of thermal expansion of the samples.

\footnotetext{
*E-mail: pursky_o@ukr.net
} 


\section{Calculations and comparison with experiment}

In the current work we consider only the isobaric thermal conductivity. The study of isobaric thermal conductivity is very important for the practical use of substances under real-life conditions. In the solidified inert gases such as $\mathrm{Ar}, \mathrm{Kr}$, and $\mathrm{Xe}$, the phonon-phonon interactions turn out to be the main mechanism determining the value and the temperature dependence of the thermal conductivity $\Lambda(T)$ at the Debye temperature and higher (He and Ne melt at temperatures much below $\left.\Theta_{\mathrm{D}}[3]\right)$. Figure 1 shows the isobaric thermal conductivity of $\mathrm{Ar}, \mathrm{Kr}$, and Xe (black squares) [5]. It decreases with the increase of temperature as $\Lambda_{p}^{\mathrm{Ar}} \propto T^{-1.6}, \Lambda_{p}^{\mathrm{Kr}} \propto T^{-1.3}$, and $\Lambda_{p}^{\mathrm{Xe}} \propto T^{-1.5}$. The most obvious interpretation of this phenomenon is the effect of thermal expansion.
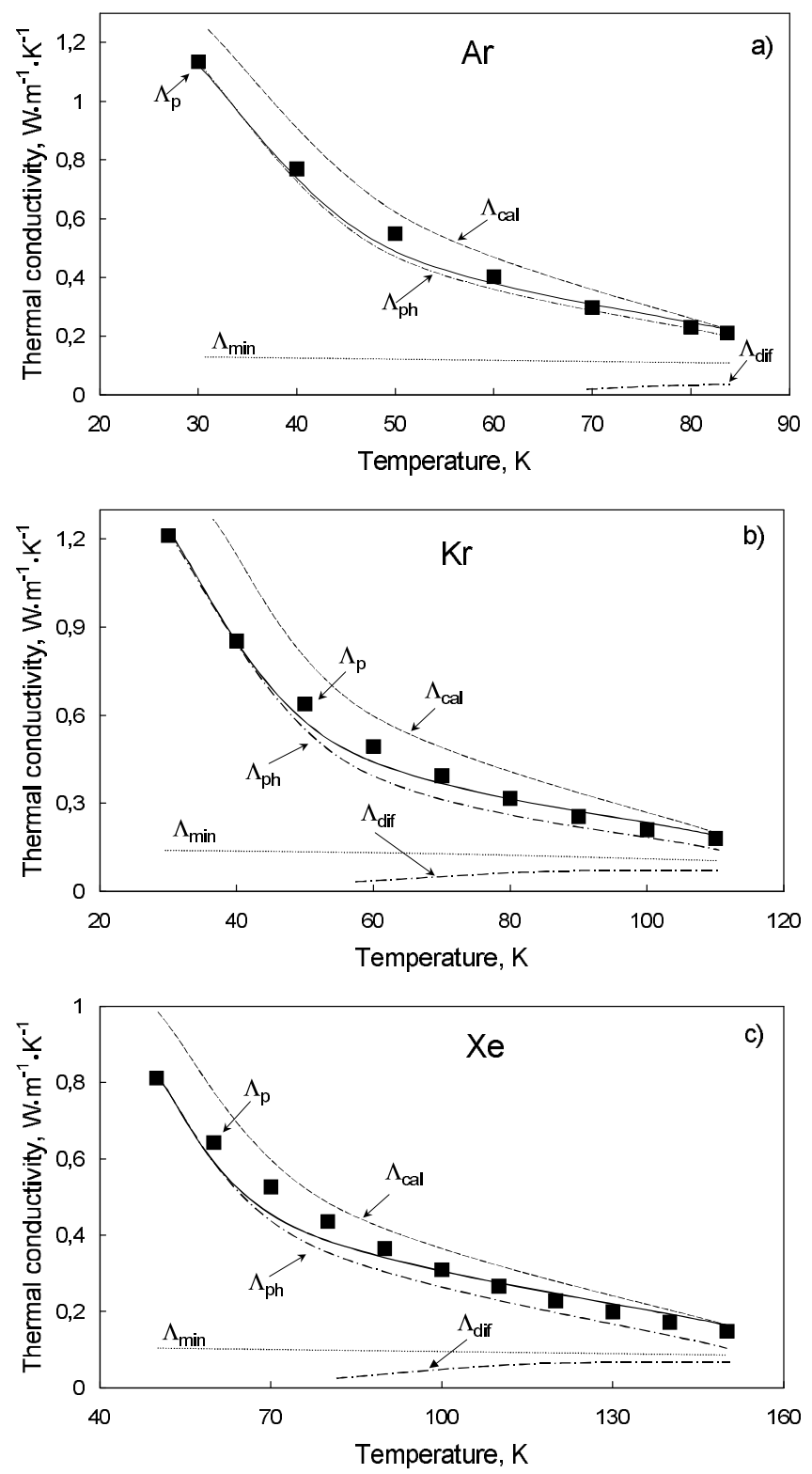

Figure 1. Isobaric thermal conductivity $\Lambda_{\mathrm{p}}$ of solids $\operatorname{Ar}(\mathrm{a}), \operatorname{Kr}(\mathrm{b})$ and $\mathrm{Xe}(\mathrm{c})$. The solid lines are the fitting curves for isobaric thermal conductivity. $\Lambda_{\mathrm{ph}}$ and $\Lambda_{\mathrm{dif}}$ are contributions of phonons and "diffusive" modes to heat transfer, respectively. The lower limit of the thermal conductivity $\Lambda_{\min }$ is calculated according to equation (2). $\Lambda_{\text {cal }}$ is the thermal conductivity calculated according to equation (1). 
We begin our quantitative analysis of experimental data with a simple approach where the heat transfer is described in the well-known theoretical $1 / T$ dependence and takes into account the effect of thermal expansion. In these calculations we use the expression of Leibfried and Shlömann [8]:

$$
\Lambda_{\text {cal }}=K\left(\frac{k_{\mathrm{B}}}{\hbar}\right)^{3} \frac{m a \Theta_{\mathrm{D}}^{3}}{\gamma^{2} T},
$$

where $a$ is the lattice parameter, $m$ is the atomic mass, $\gamma$ is the Grüneisen parameter, $K$ is the numerical coefficient (table 2). Note that the values $a, \gamma$, and $\Theta_{\mathrm{D}}$ depend on temperature at a constant pressure due to the thermal expansion of the samples (see table 1).

Table 1. The values used at calculations of $\Lambda_{\text {cal }}, \Lambda_{\mathrm{ph}}$, and $\Lambda_{\text {dif }}$.

\begin{tabular}{|c|c|c|c|c|}
\hline$T, \mathrm{~K}$ & $v, \mathrm{~m} / \mathrm{s}$ & $a, 10^{-10} \mathrm{~m}$ & $\Theta_{\mathrm{D}}, \mathrm{K}$ & $\gamma$ \\
\hline \multicolumn{5}{|c|}{$\mathrm{Ar}$} \\
\hline 30 & 1021.5 & 3.36 & 90.4 & 2.79 \\
\hline 40 & 999.6 & 3.37 & 88.1 & 2.81 \\
\hline 50 & 997.2 & 3.39 & 85.8 & 2.88 \\
\hline 60 & 933.3 & 3.40 & 81.6 & 2.84 \\
\hline 70 & 889.4 & 3.42 & 77.3 & 2.78 \\
\hline 80 & 844.9 & 3.44 & 73.1 & 2.74 \\
\hline 83.7 & 801.1 & 3.45 & 69.1 & 2.74 \\
\hline \multicolumn{5}{|c|}{$\mathrm{Kr}$} \\
\hline 30 & 843.2 & 3.57 & 70.0 & 2.83 \\
\hline 40 & 834.3 & 3.58 & 69.1 & 2.83 \\
\hline 50 & 817.9 & 3.59 & 67.5 & 2.84 \\
\hline 60 & 802.3 & 3.60 & 66.1 & 2.83 \\
\hline 70 & 781.2 & 3.61 & 64.1 & 2.81 \\
\hline 80 & 758.8 & 3.62 & 62.1 & 2.76 \\
\hline 90 & 734.4 & 3.64 & 59.8 & 2.75 \\
\hline 100 & 708.9 & 3.65 & 57.5 & 2.79 \\
\hline 110 & 684.4 & 3.67 & 55.3 & 2.94 \\
\hline \multicolumn{5}{|c|}{$\mathrm{Xe}$} \\
\hline 50 & 804.2 & 3.88 & 61.5 & 2.73 \\
\hline 60 & 786.9 & 3.89 & 60.1 & 2.82 \\
\hline 70 & 772.8 & 3.90 & 58.8 & 2.85 \\
\hline 80 & 758.5 & 3.91 & 57.6 & 2.86 \\
\hline 90 & 744.2 & 3.92 & 56.4 & 2.90 \\
\hline 100 & 729.6 & 3.93 & 55.1 & 2.92 \\
\hline 110 & 715.1 & 3.94 & 53.9 & 2.96 \\
\hline 120 & 700.7 & 3.95 & 52.7 & 2.98 \\
\hline 130 & 687.3 & 3.96 & 51.5 & 2.99 \\
\hline 140 & 672.8 & 3.97 & 50.2 & 3.00 \\
\hline 150 & 660.3 & 3.99 & 49.1 & 3.02 \\
\hline
\end{tabular}

The results of calculations carried out according to equation (1) are depicted in figure 1 as dashed lines. The necessary initial data were taken from [5,7,9-13]. The temperature dependences of the values used in the calculations are listed in table 1 . As it is seen in figure 1 the calculated thermal conductivity $\Lambda_{\text {cal }}$ decreases with the temperature increase more rapidly than the experimental one $\left(\Lambda_{\text {cal }}^{\mathrm{Ar}} \propto T^{-1.7}, \Lambda_{\text {cal }}^{\mathrm{Kr}} \propto T^{-1.5}, \Lambda_{\text {cal }}^{\mathrm{Xe}} \propto T^{-1.8}\right)$. These results showed that the experimental isobaric thermal conductivity of solid $\mathrm{Ar}, \mathrm{Kr}$, and $\mathrm{Xe}$ could not be completely explained by taking into account the processes of thermal expansion of samples only. It led us to the suggestion that such a behavior of thermal conductivity (figure 1) can be related to the thermal conductivity approaching its lower limit. The model of the minimum thermal conductivity $\Lambda_{\text {min }}$ proceeds from the assumption that all the excitations are weakly localized in the region whose sizes are half of the phonon wavelength $\lambda / 2$. Consequently, the vibrational excitations can hop from site to site 
Table 2. Debye model parameters of thermal conductivity used in the simulation, and relations between the minimal values of the experimental thermal conductivity $\Lambda_{\min }^{\exp }$ and lower limit of the thermal conductivity $\Lambda_{\min }$ are calculated according to (2).

\begin{tabular}{|c|c|c|c|c|}
\hline Substance & $K$ & $A, 10^{-16} \mathrm{~s} / \mathrm{K}$ & $\alpha$ & $\Lambda_{\min }^{\exp } / \Lambda_{\min }$ \\
\hline \hline $\mathrm{Ar}$ & 1.93 & 4.2 & 1.1 & 1.65 \\
$\mathrm{Kr}$ & 2.18 & 3.5 & 1.7 & 1.87 \\
$\mathrm{Xe}$ & 2.16 & 2.9 & 1.6 & 1.89 \\
\hline
\end{tabular}

through thermal diffusion [14]. In this case the $\Lambda_{\min }$ can be written as

$$
\Lambda_{\min }=\left(\frac{\pi}{6}\right)^{1 / 3} k_{\mathrm{B}} n^{2 / 3} v\left(\frac{T}{\Theta_{\mathrm{D}}}\right)^{2} \int_{0}^{\Theta_{\mathrm{D}} / T} \frac{x^{3} e^{x}}{\left(e^{x}-1\right)^{2}} \mathrm{~d} x
$$

where $\Theta_{\mathrm{D}}=v\left(\hbar / k_{\mathrm{B}}\right)\left(6 \pi^{2} n\right)^{1 / 3}, v$ is the polarization-averaged sound velocity, and $n$ is the number of atoms per unit volume. From figure 1 it can also be noted that the experimental thermal conductivity of solid Ar, Kr, and Xe approaches its lower limit at premelting temperatures, being no more than twice that value $\Lambda_{\min }$, calculated using the equation (2) (see table 2).

The last one, qualitatively conforms to the case of strong phonon scattering, when the meanfree path of vibrational modes is substantially limited and approaches the phonon wavelength. In this respect, in order to quantitatively describe the temperature dependences of isobaric thermal conductivity of solid Ar, Kr, and Xe, we used the Debye model of the heat transfer [2] and Roufosse and Klemens assumption [15] concerning the lower limit of the phonon scattering length. According to the Debye formalism, the lattice thermal conductivity is determined by integrating over all angular frequencies $\omega$ :

$$
\Lambda=\frac{k_{\mathrm{B}}}{2 \pi^{2} v^{2}} \int_{0}^{\omega_{\mathrm{D}}} l(\omega) \omega^{2} \mathrm{~d} \omega
$$

where $\omega_{\mathrm{D}}$ is the Debye frequency $\left(\omega_{\mathrm{D}}=\left(6 \pi^{2}\right)^{1 / 3} v / a\right)$, and $l(\omega)$ is the phonon mean free path determined by the $U$-processes at $T \geqslant \Theta_{\mathrm{D}}$, and for the perfect crystal it can be written as

$$
\begin{aligned}
& l_{u}(\omega)=v / A T \omega^{2}, \\
& A=\frac{18 \pi^{3}}{\sqrt{2}} \frac{k_{\mathrm{B}} \gamma^{2}}{m a^{2} \omega_{\mathrm{D}}^{3}} .
\end{aligned}
$$

Expression (4) is not applicable if $l(\omega)$ becomes of the order or smaller than half of the phonon wavelength $\lambda / 2=\pi v / \omega$. The problem is then to determine the density of states and the eigenfrequencies of these excitations. A similar situation was considered previously for the case of $U$ processes [15]. In this case, the mean free path of high-frequency phonons for frequencies lager than a frequency $\omega_{0}$ becomes constant and comparable with an interatomic distance, whereas the mean free path of low-frequency phonons is determined by equation (4) as before:

$$
l(\omega)=\left\{\begin{array}{cc}
v / A \omega^{2} T & 0 \leqslant \omega \leqslant \omega_{0}, \\
\alpha \pi v / \omega & \omega_{0}<\omega \leqslant \omega_{\mathrm{D}},
\end{array}\right.
$$

where $\alpha$ is the numerical coefficient of the order of unity. We have assumed the excitations whose frequencies are above the phonon mobility edge $\omega_{0}$ to be "localized" or "diffusive". Since completely localized modes do not contribute to the thermal conductivity, we suppose that the localization is weak and the excitations can hop from site to site diffusively, as it was suggested by Cahill and Pohl [14]. The frequency $\omega_{0}$ can be expressed from the equations $(4,6)$ as

$$
\omega_{0}=1 / \alpha \pi A T \text {. }
$$


The integral of thermal conductivity (3) is subdivided into two parts describing the contributions to the heat transfer from the low-frequency phonons and high-frequency "diffusive" modes:

$$
\Lambda=\Lambda_{\mathrm{ph}}+\Lambda_{\mathrm{loc}}
$$

In the high-temperature limit $\left(T \geqslant \Theta_{\mathrm{D}}\right)$ these contributions are as follows:

$$
\begin{gathered}
\Lambda_{\mathrm{ph}}=\frac{k_{\mathrm{B}} \omega_{0}}{2 \pi^{2} v A T}, \\
\Lambda_{\mathrm{dif}}=\frac{\alpha k_{\mathrm{B}}}{4 \pi v}\left(\omega_{\mathrm{D}}^{2}-\omega_{0}^{2}\right) .
\end{gathered}
$$

The computer fitting of the thermal conductivity using equations (8-10) was performed by varying the coefficients $A$ and $\alpha$ using the least squares method. The parameters of the Debye model for thermal conductivity used in the fitting as well as the fitted values $A$ and $\alpha$ are listed in table 1 and table 2 . The fitting results for isobaric thermal conductivity of solids $\mathrm{Ar}, \mathrm{Kr}$, and Xe are shown in figure 1 (solid line). The same figure shows the contributions (dot-and-dash lines) to the heat transfer from the low-frequency phonons $\Lambda_{\mathrm{ph}}$ and the high-frequency "diffusive" modes $\Lambda_{\text {dif }}$ (calculated by equations (9), (10)). The dotted line shows the lower limit of thermal conductivity $\Lambda_{\min }$ (2) calculated for the isobaric case according to Cahill and Pohl, within the framework of the Einstein model of heat transfer directly from atom to atom [14]. It can be seen from figure 1, that the results obtained taking account the effect of the thermal expansion and "diffusive" heat transfer fit the experimental dependences well, and the differences do not exceed $7 \%$. While calculating we used the assumption that the minimal phonon mean-free path is equal to one half of the wavelength. However, it should be noted that this is only one of the possible assumptions. For example, Slack [16] supposed that the scattering length is equal to the phonon wavelength.

\section{Conclusion}

To summarize, we can say that the data of this study are helpful in understanding the heat transfer mechanisms in dielectric crystals under isobaric conditions. To begin with, our results, demonstrate that the isobaric thermal conductivity of rare gas solids can be described in a model, where the heat is transferred by low-frequency phonons and above the phonon mobility edge by "diffusive" modes migrating randomly from site to site. Besides, the present model takes into account the thermal expansion of the samples. The results also indicate a considerable effect of the thermal expansion and insignificant heat transfer by "diffusive" modes. The quantitative analysis showed that the thermal conductivity of solidified $\mathrm{Ar}, \mathrm{Kr}$, and $\mathrm{Xe}$ approaches its lower limit at premelting temperatures.

Based on these studies it seems reasonable to conclude that the main cause of considerable deviations of the isobaric thermal conductivity of rare gas solids from the dependence $1 / T$ is the thermal expansion of the samples.

\section{Acknowledgements}

This study was supported by the Ukrainian Ministry of Education and Science, Project F7/2862001. 


\title{
References
}

1. Purskii O.I., Zholonko N.N., Konstantinov V.A. Fiz. Nizk. Temp., 2003, 29, 1021 [Low Temp. Phys., 2003, 29, 771].

2. Berman R. Thermal Conduction in Solids. Clarendon Press, Oxford, 1976.

3. Manzhelii V.G., Freiman Y.A. Physics of Cryocrystals, Woodbury. AIP Press, New York, 1997.

4. Konstantinov V.A., Manzhelii V.G., Strzhemechnyi M.A., Smirnov S.A. Physica B, 2000, 291, 59.

5. Krupskii I.N., Manzhelii V.G. Zh. Eksp. Teor. Fiz., 1968, 55, 2075 [Sov. J. JETP, 1968, 55, 1097].

6. Ranninger J. Phys. Rev. A., 1965, 140, 2031.

7. Clayton F., Batchelder D.N. J. Phys. Chem., 1973, 6, 1213.

8. Leibfreid G., Shlomann E. Nachr. Akadem. Wiss. Gottingen, Math. Phys., 1954, 2A, 71.

9. Christen D.K., Pollac G.L. Phys. Rev. B., 1975, 12, 3380.

10. Konstantinov V.A., Manzhelii V.G., Strzhemechny M.A., Smirnov S.A. Fiz. Nizk. Temp., 1988, 14, 90 [Low Temp. Phys., 1988, 14, 48].

11. Granfors P.R., Macrander A.T., Simmons R.O. Phys. Rev., 1981, 24, 4753.

12. Voitovich E.I., Tolkachev A.M., Manzhelii V.G. J. Low Temp. Phys., 1971, 5, 435.

13. Klein M.L., Venables J.A. Rare gas solids. Acad. Press, London 1977.

14. Cahill D.G., Watson S.K., Pohl R.O. Phys. Rev., 1992, B46, 6131.

15. Roufosse M.C., Klemens P.G. J. Geophys. Res., 1994, 79, 703.

16. Slack G.A., Solid State Phys., 1979, 34, 1.

\section{Внесок теплового розширення та “дифузних" мод в ізобарну теплопровідність кристалів інертних газів}

\author{
О.І.Пурський ${ }^{1}$, В.А.Константінов² \\ 1 Київський національний університет ім. Тараса Шевченка, кафедра молекулярної фізики, \\ просп. Глушкова, 6, Київ, 03022, Україна \\ 2 Фізико-технічний інститут низьких температур НАН України, просп. Леніна, 47, Харків 61103, Україна
}

Отримано 11 грудня 2006 р.

\begin{abstract}
Теоретична модель адаптована для опису експериментальних результатів, отриманих для ізобарної теплопровідності кристалів інертних газів. Ізобарна теплопровідність кристалів інертних газів аналізується в рамках наближення Дебая із врахуванням впливу теплового розширення. Запропонована модель, в якій тепло переноситься фононами, а вище від межі рухливості фононів - "дифузними" модами, що мігрують випадковим чином з вузла на вузол. Межа рухливості фононів $\omega_{0}$ визначається із умови, що довжина вільного пробігу фонона, котра визначається U-процесами, не може стати меншою за половину довжини хвилі.
\end{abstract}

Ключові слова: теплопровідність, фононна взаємодія, “дифузні” моди

PACS: $66.70+f, 63.20 .2 s$ 